\title{
CONTROLE DOS INCÊNDIOS FLORESTAIS PELO CORPO DE BOMBEIROS DE SANTA CATARINA: DIAGNÓSTICO E SUGESTÕES PARA SEU APRIMORAMENTO
}

\author{
Walter Parizotto ${ }^{1}$, Ronaldo Viana Soares ${ }^{2}$, Antonio Carlos Batista ${ }^{2}$, Nilton José Sousa ${ }^{2}$ \\ ${ }^{1}$ Oficial do Corpo de Bombeiros de Santa Catarina, M.Sc., Xanxere, SC, Brasil - parizotto@hotmail.com \\ ${ }^{2}$ Eng. Florestal, Dr., Depto. de Ciências Florestais, UFPR, Curitiba, PR, Brasil - rvsoares@ufpr.br - batistaufpr@ufpr.br - nilton@ufpr.br \\ Recebido para publicação: 20/12/2006 - Aceito para publicação: 02/04/2008
}

\begin{abstract}
Resumo
O estado de Santa Catarina estabeleceu constitucionalmente que o Corpo de Bombeiros Militar é o órgão responsável pelas ações de controle de incêndios florestais em seu território. Este trabalho apresenta uma análise da situação atual desse órgão, visando principalmente avaliar as suas condições operacionais para fazer frente aos incêndios florestais. Para atingir esse objetivo, foram avaliadas as ações preventivas, os programas de formação de pessoal, as normas para aquisição de equipamentos e os materiais disponíveis. Foi feita também uma análise da legislação pertinente aos incêndios florestais no estado. Essas ações foram comparadas com preceitos doutrinários sobre os temas levantados na revisão bibliográfica. $\mathrm{O}$ trabalho apresenta também um levantamento do número de incêndios florestais ocorridos e registrados no período de 2000 a 2004, de acordo com dados obtidos através de uma pesquisa junto às organizações de bombeiros em atividade no estado. Ao final, é apresentada uma proposta técnica com o objetivo de servir de base para a estruturação do setor de prevenção e combate a incêndios florestais no estado de Santa Catarina, principalmente pelo Corpo de Bombeiros, salientando aspectos relacionados a equipamentos, formação de pessoal e adequação das normas técnicas.
\end{abstract}

Palavras-chave: Incêndios florestais; Corpo de Bombeiros; Santa Catarina; proteção florestal.

\begin{abstract}
The control of forest fires by the fire department of Santa Catarina State: diagnosis and suggestions for its improvement. The State of Santa Catarina constitutionally established that the Military Fire Department is the responsible agency for forest fire control actions in its territory. This research presents an analysis of the agency current situation in order to evaluate its operational conditions to face forest fire suppression activities. To reach this objective, preventive action, staff formation programs, equipment acquisition regulations, and available materials were analyzed. It was also carried out an analysis of the pertinent legislation on forest fires in the State. These issues were compared to similar situations found in the literature. This research also presents forest fires occurrences statistics registered in the State in the period 2000 to 2004. These data were obtained through questionnaires filled out by the regional Fire Departments in activity within the State. Finally, it develops a technical proposal whose objective is to serve as a basis for the forest fire prevention and suppression sector organization in the State of Santa Catarina, mainly for the Military Fire Department, focusing on aspects of equipment needed, staff formation, and technical norms adequacy.

Keywords: Forest fires; Fire Department; Santa Catarina State; forest protection.
\end{abstract}

\section{INTRODUÇ̃̃̃O}

Os incêndios se constituem, sem dúvida, na maior ameaça para os povoamentos florestais e as florestas naturais. No entanto, o fogo, sempre esteve presente na Terra, influindo de maneira significativa em vários aspectos da vida humana. Atualmente, porém, os incêndios florestais têm atingido níveis preocupantes, pois ameaçam a manutenção da biodiversidade, o rendimento sustentado das florestas, as benfeitorias e até mesmo vidas humanas. 
Incêndio florestal pode ser definido como uma combustão sem controle que se propaga consumindo os combustíveis naturais de uma floresta, tendo como principal característica o fato de propagar-se livremente, respondendo apenas às variações do ambiente e às influências derivadas dos combustíveis vegetais, do clima e da topografia (BATISTA; SOARES, 2003). Velez (2000) define incêndio florestal como o fogo descontrolado que queima uma floresta, seja de origem natural, seja provocado. Já Fonseca; Ribeiro (2003) definem incêndio florestal como a ocorrência de fogo em qualquer forma vegetativa, cujas causas vão de naturais a criminosas, podendo também estar associadas à forma acidental e, portanto, inesperada pelo proprietário ou responsável pela área atingida.

O registro de incêndios florestais é fundamental para se conhecer o problema que tal fenômeno causa em uma floresta nativa ou plantada, não raramente ignorado em sua plenitude. É fundamental saber onde ocorrem os incêndios, quando eles ocorrem e conhecer suas principais causas, porque, ao se conhecerem as causas, pode-se estabelecer um meio eficaz para prevenir ou minimizar suas conseqüências (SANTOS, 2004).

As causas de um incêndio podem variar muito em cada região, e se faz necessário conhecer outros aspectos que influenciam esses eventos. É consenso que não existem dados estatísticos ou estudos que mostrem uma classificação das causas ou tracem um perfil dos incêndios florestais para o estado de Santa Catarina, assim como para o Brasil. O conhecimento das causas e da freqüência dos incêndios florestais é de extrema importância, principalmente levando-se em consideração que o ponto de partida para a elaboração dos planos de prevenção é saber quem (ou o que) iniciou o fogo (SANTOS, 2004).

A prevenção dos incêndios florestais é, segundo Velez (2000), um conjunto de medidas que visa anular ou reduzir a probabilidade de que o fogo inicie e limitar seus efeitos caso ele ocorra, ou seja, evitar o início ou dificultar a propagação. Ainda segundo Velez (2000), as atividades preventivas podem ser classificadas em dois grupos: prevenção das fontes de fogo e prevenção da propagação do fogo. Botelho (1996) descreve a prevenção como sendo um conjunto de ações que pretendem evitar que um sinistro ocorra. No caso dos incêndios florestais, são ações necessárias, medidas ou dispositivos que impedem a origem das causas de incêndios evitáveis ou minimizam os seus efeitos e prejuízos. Já Heikkila (1993) resumidamente diz que prevenção é um conjunto de medidas para reduzir o número de incêndios florestais indesejáveis e descontrolados.

O Brasil possui uma legislação abrangente sobre a questão dos incêndios florestais e queimadas, que satisfaz as necessidades no que diz respeito à proteção legal do meio ambiente. Mas a proteção das florestas somente é efetiva quando feita através da prevenção, pois não existe maneira melhor de se combater um incêndio do que evitando que ele exista. Soares; Batista (2001b) afirmam que um incêndio é resultado de uma combinação crítica de circunstâncias que poderiam ser evitadas ou impedidas de acontecer. Maus (1999) diz também, com muita propriedade, que não há nenhuma glória de combater um incêndio que poderia ter sido evitado.

Criado em 1926, o Corpo de Bombeiros Militar do estado de Santa Catarina (CBMSC) possui, dentre as várias atribuições legais de salvaguarda de pessoas e bens, o dever legal de fiscalizar e aprovar projetos preventivos contra incêndios em áreas com vegetação nativa, de reflorestamento, de plantações florestais, bem como as ações de controle de incêndios e atuação em qualquer sinistro que venha a ocorrer em qualquer dessas áreas.

Apesar da deficiência técnica na formação humana, carência de equipamentos e leis difusas, o CBMSC vem atendendo um significativo número de incêndios florestais por ano. Além do Corpo de Bombeiros Militar, o estado de Santa Catarina possui ainda organizações de bombeiros privados, designados como bombeiros voluntários, que também executam o mesmo serviço.

Os objetivos deste trabalho consistiram em analisar as ocorrências de incêndios florestais registrados pelo Corpo de Bombeiros de Santa Catarina, fazer um diagnóstico de suas condições operacionais, fazer um levantamento das normas legais vigentes, através do estudo da legislação pertinente aos incêndios florestais, e apresentar uma proposta técnica que sirva de base para a estruturação do setor de prevenção e combate de incêndios florestais do Corpo de Bombeiros do estado de Santa Catarina, principalmente no que se refere às questões dos equipamentos, da formação de pessoal e da adequação de suas normas técnicas.

\section{MATERIAIS E MÉTODOS}

\section{Características da área de estudo}

Localizado na região Sul do país, com uma área de $95.318 \mathrm{~km}^{2}$, correspondente a $1,11 \%$ da área total do Brasil, o estado de Santa Catarina possui atualmente $29,14 \%$ de sua área cobertos com vegetação 
primária e secundária de porte arbóreo e arbustivo, e 4,14\% com reflorestamento, principalmente pinus e eucaliptos (FATMA, 2003). Os percentuais apresentados para a vegetação primária correspondem a pouco mais de 27.775 hectares, distribuídos em 44 unidades de conservação ambiental, estaduais e federais.

O estado de Santa Catarina apresenta vocação para o setor florestal, principalmente nas terras pobres do planalto serrano, impróprias para agricultura de grãos mas adequadas para a silvicultura. As antigas fazendas de gado deram lugar às florestas de pinus. Nas terras férteis e onduladas do oeste, nasce uma nova fronteira da silvicultura, que se apresenta como alternativa para a crise da agricultura de subsistência e para a impossibilidade de mecanização dos terrenos acidentados.

A área reflorestada de Santa Catarina, que em 2001 era projetada em 350.000 hectares, em 2005 superou todas as projeções, atingindo quase 460.000 hectares, e vem crescendo em um ritmo surpreendente todos os anos (FREY, 2003). Os investimentos pelas empresas do setor de papel e celulose já fazem do estado de Santa Catarina a segunda principal área plantada com pinus do Brasil. A atividade florestal apresenta atualmente grande importância para o desenvolvimento econômico do estado.

\section{Metologia da pesquisa}

Este estudo foi desenvolvido em duas fases distintas. A primeira teve por objetivo quantificar e diagnosticar as condições operacionais, a eficácia das normas vigentes através do estudo da legislação e a quantidade de incêndios florestais atendidos pelo Corpo de Bombeiros Militar do estado de Santa Catarina. Para atingir tais propósitos, foi necessário relacionar as diversas organizações de bombeiros existentes no estado. Na seqüência, realizou-se uma pesquisa por meio de questionários enviados para todas as organizações de bombeiros atuantes em Santa Catarina e também foram feitas entrevistas informais com alguns oficiais que trabalham com essa temática. A segunda fase consistiu no aprofundamento da pesquisa teórica, que buscou subsídios para a análise dos dados coletados. Para tanto, foi necessário considerar os sistemas de prevenção e combate aos incêndios florestais, os equipamentos e meios indicados, a legislação relacionada à prevenção e os programas institucionais para o controle de incêndios florestais. Entre $1^{\circ}$ e 15 de março de 2005, foram elaborados e enviados 100 questionários para as organizações de bombeiros que operam no estado. Os questionários foram enviados através de correio eletrônico para as organizações de bombeiros militares e através de correspondência postada para as organizações de bombeiros privados. $\mathrm{Na}$ ocasião, o estado de Santa Catarina contava com 70 organizações de bombeiros militares e 30 organizações de bombeiros privados.

\section{RESULTADOS E DISCUSSÃO}

Quarenta e cinco corpos de bombeiros, sendo 44 militares e 1 privado, responderam aos questionários. Quando questionados sobre os equipamentos exclusivos para o combate a incêndios florestais, as organizações de bombeiros que responderam à pesquisa informaram possuir os equipamentos listados a seguir, sendo que os valores apresentados correspondem à somatória geral das organizações pesquisadas (Tabela 1).

\section{Política de prevenção e combate aos incêndios florestais do Corpo de Bombeiros}

$\mathrm{O}$ resultado da pesquisa, com relação à estimativa do risco de incêndios florestais, mostrou uma resposta negativa por 44 corpos de bombeiros, ou seja, essas organizações não possuem nenhum mecanismo de ação preventiva aos incêndios florestais. Apenas uma organização informou estimar o risco de incêndios, utilizando o índice de perigo FMA (Fórmula de Monte Alegre). Isso demonstra uma postura pró-ativa dos corpos de bombeiros de Santa Catarina, que só atuam depois do fogo estabelecido, não havendo um planejamento prévio para as ocasiões em que o risco aumenta.

Nenhuma das organizações pesquisadas desenvolve programa específico nas épocas de risco alto ou muito alto. Algumas afirmaram desenvolver apenas ações educativas, através de folders e palestras, sem um programa direcionado às épocas em que o risco se acentua.

\section{Política de formação humana voltada aos incêndios florestais do Corpo de Bombeiros}

O Corpo de Bombeiros Militar de Santa Catarina possui normas de ensino reguladas através das Instruções Gerais para o Ensino e Pesquisa (IG 40-01-BM), que tratam da formação dentro da corporação em diversos níveis. A formação inicial se dá em três níveis: a formação de oficiais, reconhecida como 
nível superior, com curso próprio, com duração de três anos; a formação de sargentos, com duração de um ano e seis meses e a formação de soldados, com duração de um ano.

Tabela 1. Equipamentos de combate a incêndios florestais dos corpos de bombeiros (CBs) do estado de Santa Catarina.

Table 1. Forest fire suppression equipment used by the Fire Department of Santa Catarina State.

\begin{tabular}{lccc}
\hline Descrição & Quantidade & $\begin{array}{c}\text { Número de corpos de } \\
\text { bombeiros que utilizam } \\
\text { os equipamentos }\end{array}$ & $\begin{array}{c}\text { Porcentagem de CBs } \\
\text { que possuem os } \\
\text { equipamentos }\end{array}$ \\
\hline Motosserra & Equipamentos de uso múltiplo \\
Enxada & 84 & 45 & 100 \\
Foice & 189 & 45 & 100 \\
Pá & 132 & 45 & 100 \\
Binóculo & 140 & 45 & 100 \\
Apito & 46 & 38 & 84 \\
Cantil & 131 & 45 & 100 \\
Mochila & 148 & 45 & 100 \\
& 37 & 45 & 100 \\
\hline Batedores manuais (tirantes) & Equipamentos exclusivos para incêndios florestais & 100 \\
Abafadores (lâminas) & 45 & 45 & 60 \\
Queimadores (pinga-fogo) & 45 & 27 & 29 \\
Extintores costais antiincêndio & 13 & 13 & 100 \\
McLeod & 83 & 45 & 2 \\
Kit meteorológico & 1 & 1 & 2 \\
Equipamento de proteção individual & 1 & 1 & 4 \\
\hline
\end{tabular}

Conforme a IG 40-01-BM do Corpo de Bombeiros Militar de Santa Catarina, o programa adotado para a formação, principalmente de oficiais, não inclui a disciplina de controle de incêndios florestais.

Para os oficiais ainda não formados pela academia, o CBMSC prevê um curso de qualificação denominado Curso de Especialização para Bombeiros Oficiais (CEBO), no qual uma parte de controle de incêndios florestais está inserida dentro do programa da disciplina de combate a incêndio urbano, que possui uma carga horária total de 110 horas aula.

Já para o Curso de Formação de Oficiais (CFO) existe uma matéria específica chamada de incêndios especiais, cuja carga horária é de 50 horas-aula, contemplando ainda incêndio aeronáutico. Essa matéria é ministrada no $2^{\circ}$ ano do curso em questão.

Para os bombeiros voluntários associados ao Corpo de Bombeiros Militar, denominados Bombeiros Comunitários, existe um regulamento estadual que orienta a formação do pessoal. A carga horária do curso totaliza 220 horas, das quais 20 são destinadas às operações de combate a incêndios estruturais e florestais.

\section{Registros e perícias de incêndios florestais}

Observou-se que muitas organizações de bombeiros possuem dificuldade para diferenciar um incêndio florestal de incêndios em lotes urbanos e queimadas. Isso se deve ao fato de não haver codificação específica para essas situações no âmbito do CBMSC, sendo a maioria dos casos acima cadastrados no grupo I-207 (incêndio em vegetação rasteira nativa).

Um meio eficaz de se minimizar as conseqüências dos incêndios seria conhecer as causas para se fazer uma prevenção mais efetiva. No caso dos incêndios florestais, eles podem variar de região para região, porém não existem dados estatísticos específicos para o estado de Santa Catarina.

Geralmente, o homem é o principal causador dos incêndios florestais, pois a grande maioria deles é iniciada em decorrência de algum tipo de atividade humana (SANTOS, 2004). Em Santa Catarina, de forma particular, o Corpo de Bombeiros Militar procura levantar as causas dos incêndios urbanos, porém tal prática não é observada quando se trata de incêndios florestais. Por isso, o registro das 
ocorrências e as perícias para se descobrir as causas seria de grande importância para se aumentar a eficiência do controle dos incêndios florestais no estado.

\section{Monitoramento do risco de incêndios florestais em áreas potencialmente importantes}

A pesquisa realizada mostrou que apenas uma organização de bombeiro, dentre as 45 que responderam aos questionários, faz monitoramento de épocas de perigo de incêndios, através da fórmula de Monte Alegre. Sabe-se que as condições climáticas influenciam a probabilidade de ocorrência dos incêndios, que se distribuem de forma desigual ao longo dos meses. Esse monitoramento poderá possibilitar o desencadeamento de ações preventivas, como a ampliação das equipes de prontidão ou outras medidas próprias das ações de bombeiros.

\section{Unidades de conservação que necessitam de proteção}

Em Santa Catarina, foram identificadas 44 unidades de conservação com risco potencial, com formações vegetais predominantes do bioma da Floresta Atlântica. É preocupante o fato de que somente duas organizações de bombeiros, dentre as 45 pesquisadas, desenvolvem alguma atividade específica de proteção nessas áreas de risco, que são as unidades de Xanxerê, no Parque Estadual das Araucárias, e a de Lages, no Parque Nacional de São Joaquim.

\section{Diagnóstico da eficácia das normas legais vigentes através do estudo da legislação pertinente aos} incêndios florestais com reflexos no estado de Santa Catarina

Ao se avaliarem os aspectos legais que tutelam os incêndios florestais no Brasil, é necessário, preliminarmente, relacionar as questões ambientais, uma vez que o direito ambiental é um direito de interações, disperso em várias regulamentações. O direito ambiental é mais do que um novo ramo do direito, com seu próprio corpo de regras, porque tende a penetrar em todos os sistemas jurídicos existentes. Dada a sua interdisciplinaridade, é um direito de reagrupamento.

As mesmas considerações do ditame legal do meio ambiente são, por extensão, as que regem a política de fogo nas florestas brasileiras, ou seja, o princípio da conservação, o da punição e o da prevenção. Assim, quando o legislador refere-se a conceitos tutelares do meio ambiente, por extensão refere-se às florestas.

A natureza jurídica da proteção e da tutela estatal repousa na questão de que o meio ambiente é um patrimônio público a ser necessariamente assegurado e protegido, tendo em vista o seu uso coletivo (Art $2^{\circ}$ da Lei 6938/81). Ao se mencionar a expressão patrimônio público, entenda-se o conceito jurisprudencial de que se refere a bens e direitos desvinculados de expressão econômica, independentes em relação à dominialidade e representativos de valores imateriais.

O regime especial a que está submetido o meio ambiente comporta vínculos, obrigações, deveres e ônus, relativamente à disponibilidade dos bens e à possibilidade de intervenção de variado gênero por parte de órgãos da administração. Esses conceitos justificam a intervenção pública, não somente nas áreas públicas de preservação permanente, mas também nas áreas privadas diversas.

Com relação aos incêndios florestais, seguindo os princípios fundamentais do direito, segue-se em sentido amplo tudo o que a lei tutela ao meio ambiente e, mais precisamente, tudo o que de forma especial a lei trata sobre o assunto.

\section{Conflitos de normas relacionadas aos incêndios florestais}

Conforme se pode observar nas diversas descrições legais expostas, há uma confusão de leis sobre o mesmo tema. Inicialmente, o Código Florestal (1965), ainda em vigor, tipifica a prática de incêndio como contravenção penal:

Art. 26 - Constituem contravenções penais, puníveis com três meses a um ano de prisão simples ou multa de uma a cem vezes o salário-mínimo mensal do lugar e da data da infração ou ambas as penas cumulativamente:

a) destruir ou danificar a floresta considerada de preservação permanente, mesmo que em formação, ou utilizá-la com infringência das normas estabelecidas ou previstas nesta Lei; $[\ldots]$.

e) fazer fogo, por qualquer modo, em floresta e demais formas de vegetação, sem tomar as precauções adequadas. 
Em 1980, quando ainda se encontrava em vigor a Lei $\mathrm{n}^{\circ} 6803$, o Decreto $\mathrm{n}^{\circ} 14250$, trouxe para o estado de Santa Catarina uma previsão exclusiva com relação à gestão de fogos, regredindo a uma infração administrativa os crimes do código florestal.

Art. 59 - É proibido promover queimadas:

I - nas áreas de proteção especial;

II - nas zonas de reserva ambiental; e

III - nas terras de propriedade do Estado e dos Municípios.

Com o advento da Lei Ambiental 9605, a figura tipificada elevou-se à categoria de crime, descrito no Capítulo V, onde se estabelecem os crimes contra o meio ambiente.

Art 41 - Provocar incêndio em mata ou floresta:

Pena - reclusão de dois a quatro anos e multa.

Segundo Jesus (1985), crime é um fato típico e antijurídico, uma conduta humana positiva ou negativa (ação ou omissão), considerado dessa forma e descrito em lei penal e contrário ao direito.

A contravenção é um ilícito com menor poder ofensivo (JESUS, 1985), um crime "anão". Mesmo de difícil conceituação diferencial, a lei faz essa referência ao tipificar o ato antijurídico.

O conflito legal é resolvido pelos princípios gerais do direito, através do princípio do novatio legis in pejus, pelo qual a lei modifica o regime anterior, tornando o regime mais grave. A partir do momento em que ela entra em vigor, passa a vigorar o regime do tempo do crime e da irretroatividade da lei penal. No entanto, como mostra a confusão do tema, para o mesmo fato atípico são previstas três penas diferentes (Tabela 2).

Tabela 2. Quadro comparativo de normas legais.

Table 2. Comparative table of legal rules.

\begin{tabular}{|c|c|c|c|}
\hline Norma & Fato tipificado & Figura penal & Pena \\
\hline Lei 4.771 de set. 1965 & $\begin{array}{l}\text { Fazer fogo, por qualquer } \\
\text { modo, em floresta e } \\
\text { demais formas de } \\
\text { vegetação, sem tomar as } \\
\text { precauções adequadas } \\
\end{array}$ & Contravenção & $\begin{array}{c}\text { Três meses a um ano de prisão } \\
\text { simples ou multa de uma a cem } \\
\text { vezes o salário-mínimo mensal do } \\
\text { lugar e da data da infração ou ambas } \\
\text { as penas cumulativamente. }\end{array}$ \\
\hline Lei 9.605 de fev. de 1998 & $\begin{array}{l}\text { Provocar incêndio em } \\
\text { mata ou floresta. }\end{array}$ & Crime & $\begin{array}{l}\text { Reclusão de dois a quatro anos e } \\
\text { multa. }\end{array}$ \\
\hline Dec. Est. 14.250 & $\begin{array}{l}\text { Promover queimadas em } \\
\text { áreas de proteção especial, } \\
\text { zonas de reserva } \\
\text { ambiental e terras públicas }\end{array}$ & $\begin{array}{l}\text { Infração } \\
\text { administrativa }\end{array}$ & $\begin{array}{c}\text { Advertência } \\
\text { Multa } \\
\text { Restrição da linha de financiamento } \\
\text { Interdição } \\
\text { Embargo } \\
\text { Obrigação de recuperar }\end{array}$ \\
\hline
\end{tabular}

Além dos conflitos da tipificação penal, observam-se vários desencontros nos aspectos técnicos preventivos, de forma particular na construção de aceiros (Tabela 3).

Tabela 3. Quadro comparativo de previsão legal de larguras de aceiros.

Table 3. Comparative table of firebreaks width in State and Federal legislation.

\begin{tabular}{lc}
\hline Norma & Descrição \\
\hline Decreto Federal no 2.661 & $\begin{array}{c}\text { Aceiros de no mínimo três metros de largura, ampliando essa faixa quando as } \\
\text { condições ambientais, topográficas, climáticas e o material combustível assim } \\
\text { determinarem. }\end{array}$ \\
\hline $\begin{array}{c}\text { Decreto Estadual no } 14.250 \\
\text { Decreto Estadual no } 4.909\end{array}$ & $\begin{array}{c}\text { Aceiros com } 7 \text { (sete) metros de largura, sendo } 2,50 \text { m capinados e varridos e o } \\
\text { restante roçado. }\end{array}$ \\
\hline
\end{tabular}

A análise dos diversos dispositivos legais vigentes no estado de Santa Catarina mostra que ocorre uma dicotomia entre os ordenamentos, variando tecnicamente e em outros casos anulando-se em função dos princípios fundamentais do direito. 
Incêndios florestais atendidos pelos corpos de bombeiros no estado de Santa Catarina de 2000 a 2004

A partir da pesquisa realizada, foi possível traçar um perfil das ocorrências de incêndios registrados pelas organizações de bombeiros de Santa Catarina no período de 2000 a 2004 (Tabela 4). É importante destacar que os incêndios florestais aqui mencionados foram os que tiveram, de alguma forma, interferência direta do corpo de bombeiros, ou seja, foram atendidos pela corporação, que gerou e manteve arquivados os relatórios.

Tabela 4. Distribuição mensal e número total dos incêndios florestais atendidos por organizações de bombeiros de Santa Catarina de 2000 a 2004.

Table 4. Forest fires suppressed by the Santa Catarina Fire Department from 2000 to 2004.

\begin{tabular}{lrrrrrrrrrrrrrr}
\hline \multirow{2}{*}{ Ano } & \multicolumn{10}{c}{} & \multicolumn{10}{c}{ Man } & Fev & Mar & Abr & Mai & Jun & \multicolumn{1}{c|}{ Jul } & Ago & Set & Out & Nov & Dez & \multirow{2}{*}{ Total } \\
\hline 2004 & 67 & 133 & 220 & 56 & 31 & 61 & 98 & 304 & 188 & 109 & 101 & 75 & 1443 \\
2003 & 67 & 64 & 91 & 125 & 179 & 88 & 244 & 539 & 411 & 125 & 111 & 77 & 2121 \\
2002 & 73 & 80 & 69 & 67 & 48 & 48 & 71 & 121 & 155 & 48 & 56 & 46 & 882 \\
2001 & 42 & 35 & 42 & 35 & 43 & 40 & 94 & 313 & 130 & 114 & 121 & 79 & 1088 \\
2000 & 54 & 55 & 55 & 67 & 39 & 65 & 191 & 353 & 154 & 67 & 66 & 65 & 1231 \\
Total & 303 & 367 & 477 & 350 & 340 & 302 & 698 & 1630 & 1038 & 463 & 455 & 342 & 6765 \\
$\%$ & 4,5 & 5,4 & 7,1 & 5,2 & 5,0 & 4,5 & 10,3 & 24,1 & 15,3 & 6,8 & 6,7 & 5,1 & 100 \\
\hline
\end{tabular}

A freqüência dos incêndios pode ser melhor observada através da figura 1, principalmente se considerado que o conhecimento da distribuição das ocorrências através dos meses é um instrumento importante no planejamento da prevenção de incêndios florestais, por indicar em que meses do ano serão necessárias medidas de controle mais intensas (SOARES; BATISTA, 2001b).

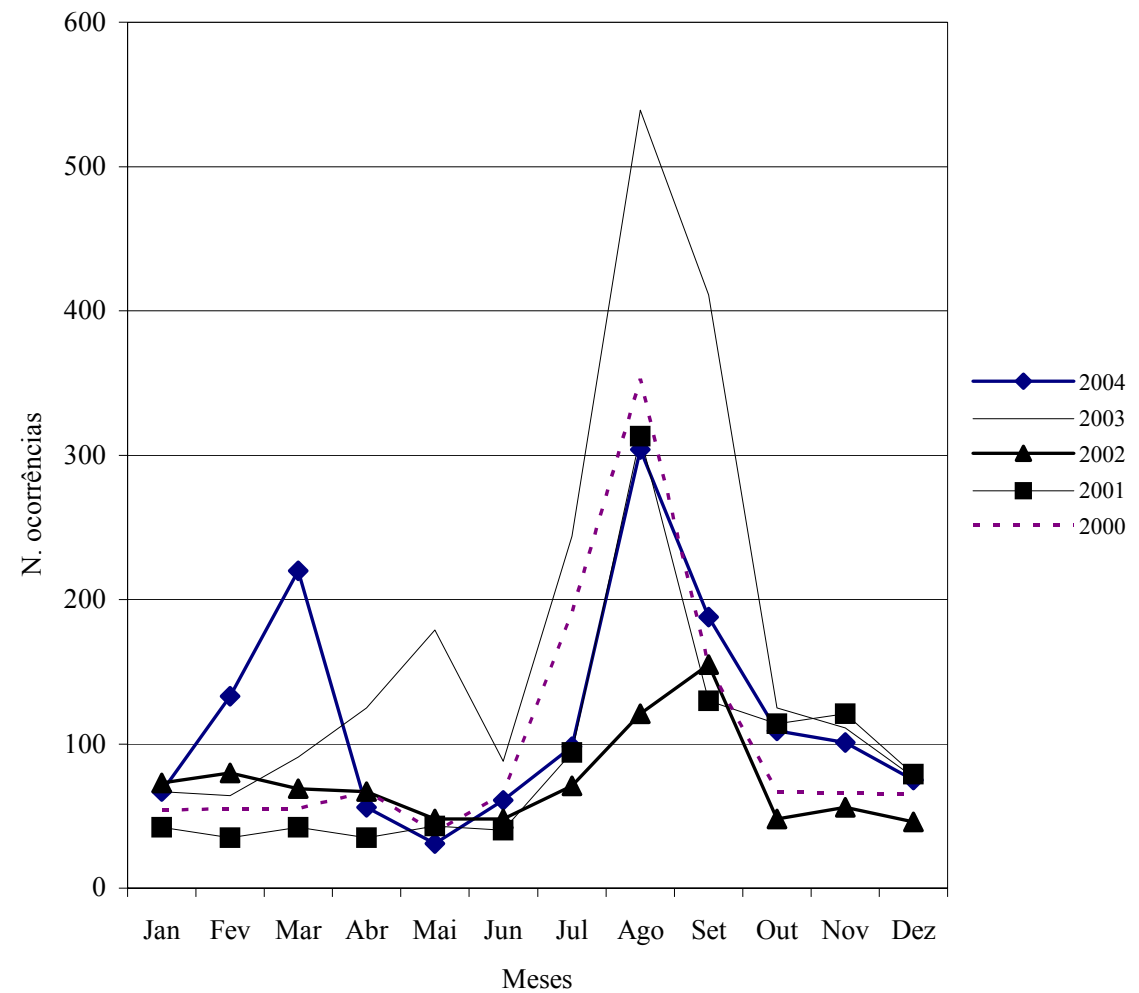

Figura 1. Freqüência mensal das ocorrências de incêndios de 2000 a 2004.

Figure 1. Monthly frequency of fire occurrences from 2000 to 2004. 
A maior incidência de incêndios foi observada nos meses de julho (10,32\%), agosto $(24,21 \%)$ e setembro (15,35\%), concentrando quase $50,00 \%$ do total de registros no período. Os menores números de ocorrências foram registrados nos meses de janeiro (4,48\%), junho (4,46\%) e dezembro (5,05\%). Essa distribuição está de acordo com o trabalho de Soares; Batista; Santos (2005), que também observaram maior incidência de incêndios no período de julho a setembro, com destaque para agosto, com $24,1 \%$ dos registros. Os porcentuais de agosto foram 28,8\% em 2000, 28,77\% em 2001, 13,72\% em 2002, 25,41\% em 2003 e $21,07 \%$ em 2004. Valores semelhantes foram observados por Soares; Batista; Santos (2005), que, estudando o perfil dos incêndios florestais em áreas protegidas no Brasil, encontraram, para o mês de agosto, 19,3\% no período de 1983 a 1987, 26,6\% no período de 1994 a 1997 e 21,8\% no período de 1998 a 2002.

Os incêndios florestais estão associados às práticas agrícolas originais e à expansão do setor no estado. Assim como o declínio da floresta natural, os incêndios em florestas no estado estão associados à evolução da lavoura. Não há ponto sem cobertura natural do estado que não ardeu em uma fogueira durante a fase de colonização. Mesmo nos dias atuais, a prática de queimadas para limpeza pré-plantio é largamente utilizada pelos agricultores na maioria das regiões do estado, o que tem contribuído para a degradação de alguns recursos naturais.

Apesar da importância dos registros do corpo de bombeiros, nem todos os incêndios registrados no estado estão computados. Um exemplo de que muitos incêndios ocorrem sem fazer parte das estatísticas da corporação foi o incêndio que, em 1999, atingiu aproximadamente $30 \%$ da área da reserva indígena Xapecó, que tem uma área de 16 mil hectares. Duas casas foram totalmente queimadas nesse incêndio, mas não houve interferência do corpo de bombeiros, que nas cidades menores e zonas rurais mais distantes possui um enfoque essencialmente urbano.

\section{Proposta técnica para a estruturação do setor de prevenção e combate de incêndios florestais no estado de Santa Catarina}

Com base na situação atual, nas respostas dos questionários e na revisão de literatura, foi elaborada uma proposta para os diversos aspectos deficitários que o Corpo de Bombeiros de Santa Catarina apresenta em sua estrutura.

\section{Equipamentos}

Vélez (2000), ao descrever as ferramentas manuais e extintoras, classifica-as em cortantes, raspantes, mistas, sufocantes e extintoras, e sugere que elas devem ser desenvolvidas especificamente para atender as características dos incêndios florestais.

A pesquisa realizada e seus resultados mostraram uma deficiência de materiais exclusivos para a atividade de incêndios florestais, com destaque para o fato de uma predominância de uso, por todas as organizações, de batedores, que são materiais de fabricação artesanal, feitos a partir de tiras de mangueiras usadas, e um desconhecimento do uso de meios químicos para o controle de incêndios.

A aquisição de materiais e a estruturação das organizações de bombeiros devem se dar conforme mostrado no fluxograma da figura 2.

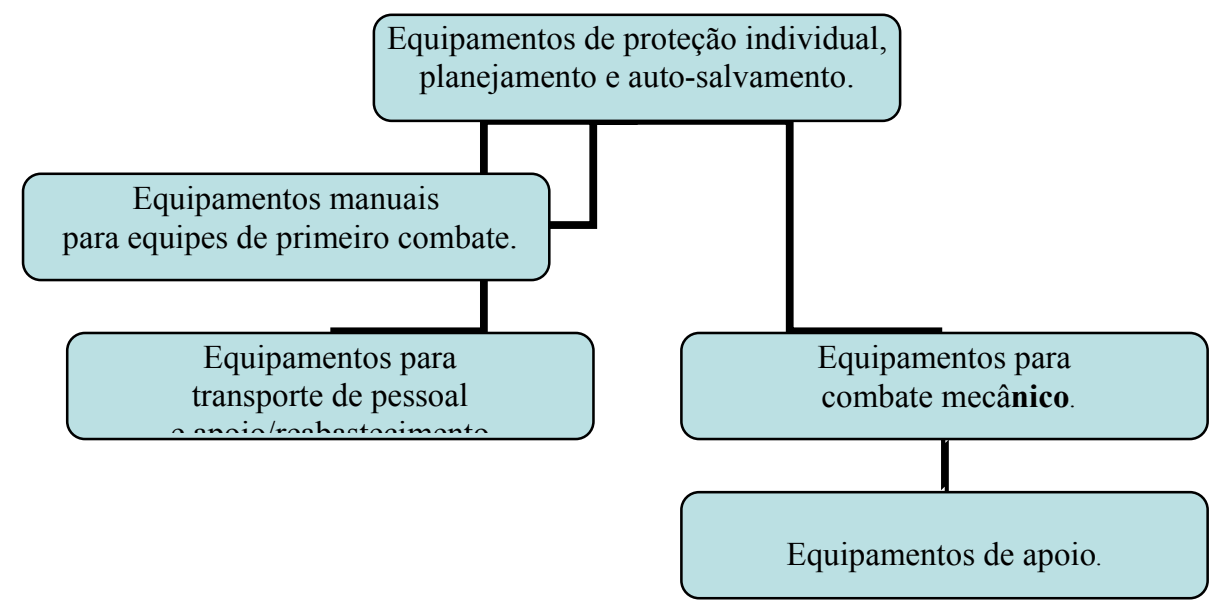

Figura 2. Fluxograma dos equipamentos de combate a incêndios.

Figure 2. Fire suppression equipment flowchart. 


\section{Índice de Perigo de Incêndio}

A possibilidade de se estimar o perigo de incêndios a partir de parâmetros meteorológicos com uma confiabilidade aceitável, com baixo custo, pode ser uma ferramenta útil para as organizações de bombeiros. Os índices representam uma ferramenta importante para que se possa predizer o perigo no tempo e no espaço, determinando as épocas de maior risco e as zonas mais perigosas (VÉLEZ, 2000). Assim, os comandantes de organizações poderão adotar medidas próprias para as épocas de perigo de incêndios, tais como:

- Distribuir, no tempo, os recursos para prevenção e extinção.

- Determinar o início de campanhas preventivas.

- Determinar o início de campanhas de vigilância.

- Estabelecer plano de defesa ou de combate.

- Estabelecer prioridades para as diversas zonas envolvidas.

- Situar ou concentrar meios de defesa e extinção.

Atualmente, estuda-se o desempenho de vários tipos de índice meteorológico de perigo de incêndios, com base numa rede própria de estações meteorológicas, e procura-se relacionar a ocorrência de incêndios com fatores socioeconômicos. Assim, no Brasil, podem-se obter estimativas seguras a partir da Fórmula de Monte Alegre (SOARES, 1972), que é mais simples do que os índices desenvolvidos em outros países, por envolver apenas duas variáveis, umidade relativa do ar e precipitação. Após alguns anos, e contando com informações sobre as ocorrências de incêndios, a FMA poderá ser adaptada para a região, a fim de melhorar seu desempenho na previsão do grau de perigo.

Existem inúmeras áreas vegetadas importantes no estado de Santa Catarina. Cada uma delas está inserida na área de atuação de uma organização de bombeiros. Sendo assim, adotando-se para os diversos quartéis um mesmo índice que permita medir o perigo de incêndios florestais, proporciona-se aos comandantes uma ferramenta útil e importante para a tomada de decisões.

A Fórmula de Monte Alegre permitirá que os bombeiros catarinenses estimem o risco de incêndios florestais e adotem medidas para minimizar seus efeitos, compor reforços nas equipes de ataque, fazer campanhas preventivas na mídia ou adotar medidas como a regulamentação de uso de parques ou outras áreas vegetadas. Assim como qualquer outro equipamento, a utilização da FMA exige treinamento e qualificação para o seu uso, o que está sugerido no programa de formação dos bombeiros.

\section{Proposta de um novo texto normativo para o Corpo de Bombeiros Militar do Estado de Santa Catarina}

As normas de segurança contra incêndios (NSCI) do CBMSC necessitam de uma alteração para que possam se ajustar às técnicas preventivas constituídas, podendo assim ser mais bem aceitas pela população e instituições florestais.

Com base nos resultados deste estudo, sugere-se que as NSCI tenham a seguinte redação:

Art. $1^{\circ}$ - Todas as áreas florestais catarinenses deverão dispor de sistema preventivo contra incêndios de acordo com seu grau de risco.

Art. $2^{\circ}$ - Para as áreas de reflorestamento cuja superfície seja igual ou superior a 250 ha, serão exigidas as seguintes adequações:

I. Planta topográfica em escala 1:10.000 da área do projeto, com locação dos talhões, aceiros, divisórias, torres (se for o caso), estradas, caminhos, construções de cercas e galpões, locais de preservação, mananciais, locais inaproveitáveis, com suas respectivas áreas, apresentadas em quadro explicativo.

II. Divisão da área plantada em talhões, conforme a tabela 5 .

Tabela 5. Relação da área máxima de talhonamento em função da declividade do terreno.

Table 5. Relationship between declivity and maximum stands sizes.

\begin{tabular}{lc}
\hline $\begin{array}{c}\text { Declividade } \\
(\%)\end{array}$ & $\begin{array}{c}\text { Área máxima } \\
\text { (ha) }\end{array}$ \\
\hline 00 a 15 & 50 \\
16 a 25 & 40 \\
26 a 35 & 35 \\
36 a 45 & 30 \\
$\geq 46$ & 25 \\
\hline
\end{tabular}


III. Construção de aceiros preventivos que terão suas larguras mínimas definidas em função da declividade do terreno, conforme a tabela 6. Em áreas de declividade acentuada, os aceiros poderão ter cobertura de gramíneas para evitar risco de erosão.

Tabela 6. Relação da largura mínima dos aceiros em função da declividade do terreno.

Table 6. Relationship between declivity and firebreaks minimum width.

\begin{tabular}{lc}
\hline $\begin{array}{c}\text { Declividade } \\
(\%)\end{array}$ & $\begin{array}{c}\text { Largura mínima } \\
(\mathbf{m})\end{array}$ \\
\hline 00 a 15 & 05 \\
16 a 25 & 10 \\
26 a 35 & 15 \\
36 a 45 & 25 \\
$\geq 46$ & 35 \\
\hline
\end{tabular}

IV. Estabelecimento de sistemas de cortinas de segurança para diminuir a intensidade do fogo, facilitando o seu combate. As faixas ou talhões sucessivos, de espécies que tenham menor inflamabilidade do que as da plantação principal, seguem o mesmo princípio da implantação dos aceiros, no entanto não dispensam aqueles.

V. Todo talhão deverá possuir sistemas de acessos principais e secundários, de modo a permitir o tráfego de algum tipo de veículo automotor. Os acessos principais devem ter no mínimo 6 metros, de maneira a permitir o tráfego nos dois sentidos, inclusive de caminhões. É fundamental que todos os acessos, principalmente nas entradas e cruzamentos, possuam sinalização indicando a posição (distância e sentido) de pontos considerados de interesse ou de risco, tais como saídas e acessos alternativos, mananciais, torres ou pontos de observação, centrais de controle e operação, habitações, linhas de transmissão, refúgios naturais ou outros específicos de cada zona de proteção.

VI. Quando o reflorestamento exceder a 250 ha, deverá ser previsto um sistema de apoio com pessoal treinado e material disponível. Nesse caso, quando o índice de perigo de incêndio alcançar as classificações "alto" e "muito alto" pela Fórmula de Monte Alegre, o sistema deve ser ativado, entrando as equipes em regime de sobreaviso e ou prontidão, conforme orientações específicas de cada responsável técnico.

VII. É fundamental que sejam previstos, para todas as florestas nativas e áreas reflorestadas, pontos de água com uso múltiplo, ou exclusivos para as ações de combate. Esses pontos de captação de água podem ser naturais ou cisternas artificiais. O dimensionamento de mananciais deve ser feito pelo parâmetro ideal de um raio máximo de 4000 metros de qualquer ponto da área a ser protegida, sendo que para essa situação o manancial deverá ser de 60 metros cúbicos. Para cada manancial, é fundamental serem assegurados no mínimo dois acessos, tão diametralmente opostos quanto possível, em condições de permitir a aproximação dos meios de combate para reabastecimento. A altura da lâmina d'água, para possibilitar a captação segura através de mangotes, deverá ter no mínimo 50 centímetros.

VIII. Toda plantação, independentemente da área, deverá possuir sistema de vigilância e detecção. Podem ser feitos através de patrulhamento móvel com aviões, veículos, motos ou cavalos, com o objetivo de descobrir e comunicar focos de incêndio às pessoas responsáveis pelo combate, de modo que sejam viabilizados os meios o mais rápido possível. $\mathrm{O}$ ideal seria cumprir esse objetivo no máximo em 15 minutos depois de iniciado o fogo. A detecção poderá ser também fixa, através de torres de observação, com operação manual ou automatizada, através de câmaras de infravermelho ou óticas.

Art. $3^{\circ}$ - Todo reflorestamento deverá adotar um plano de redução de material combustível. 
Art. $4^{\circ}$ - Para as áreas de preservação permanente, deverão ser apresentados projetos preventivos contra incêndios nos termos do Art. $2^{\circ}$, de acordo com o plano de manejo do mesmo, devendo compreender os mesmos sistemas das áreas de reflorestamento, obedecendo às particularidades da vegetação. No entanto, são obrigatórios os sistemas de mananciais e o sistema de vigilância e detecção.

Art. $5^{\circ}$ - Nas as áreas de preservação permanente e florestas nativas, será obrigatório o sistema de aceiros nas áreas limítrofes nos termos do Art. $2^{\circ}$.

\section{Proposta do programa de formação para os Bombeiros do Estado de Santa Catarina}

Os incêndios florestais muitas vezes têm causado mortes de combatentes, em várias partes do mundo, inclusive no Brasil (SOARES; BATISTA, 2007). Um exemplo recente ocorreu na Espanha, no dia 18 de julho de 2005, quando 6 bombeiros morreram ao tentar controlar um incêndio florestal (A NOTÍCIA, 2005).

Com base no que foi discutido, percebe-se que qualquer ação voltada para um programa de controle de incêndios florestais passa pela formação das pessoas envolvidas e nos currículos mínimos que devem ser analisados cuidadosamente para a formação de pessoal especializado em controle de incêndios florestais.

Com base nos programas sugeridos por Vélez (2000) e pela Associação Brasileira de Educação Agrícola Superior (ABEAS), nos cursos ministrados pela Universidade Federal do Paraná, pela Universidade Federal de Viçosa e pela Fundação Universidade Regional de Blumenau, chegou-se à proposta de um currículo para o nível de execução (soldados e sargentos), com 80 horas/aula, envolvendo os seguintes temas: danos causados pelos incêndios, teoria básica do fogo, propagação dos incêndios florestais, características do comportamento do fogo, características da cobertura florestal catarinense, equipamentos para combate a incêndios florestais, cartografia e orientação, atendimentos básicos de primeiros-socorros, queimadas controladas, técnicas de contrafogo e prevenção, combate e perícia em incêndios florestais.

O currículo mínimo para a formação de gestores de incêndios florestais, ou seja, oficiais do CBMSC, prevê um aprofundamento em alguns aspectos mais específicos, com destaque para o comportamento do fogo. Para tanto, sugere-se uma carga horária mínima de 120 horas.

\section{CONCLUSÕES}

Diante dos resultados obtidos neste trabalho, pode-se concluir que:

- O estado de Santa Catarina, através das organizações do Corpo de Bombeiros, tem registrado anualmente um significativo número de incêndios florestais.

- As quantidades e os tipos de equipamentos disponíveis pelos corpos de bombeiros no estado de Santa Catarina para fazer frente aos incêndios florestais são inadequados.

- Inexiste no estado de Santa Catarina uma política efetiva de prevenção de incêndios florestais.

- As normas legais vigentes não estão sendo cumpridas e aplicadas nas áreas de reflorestamento ou de florestas naturais, seja por não estarem em consonância com as técnicas de silvicultura adequadas, seja pela inexistência de fiscalização por parte dos corpos de bombeiros.

- Os corpos de bombeiros em Santa Catarina possuem uma conotação essencialmente urbana, não existindo equipes próprias e estruturas voltadas para o setor florestal.

- A proposta técnica cujo objetivo é a estruturação do setor de prevenção e combate de incêndios florestais no estado de Santa Catarina, principalmente pelo Corpo de Bombeiros Militar, é viável e necessária.

\section{REFERÊNCIAS}

A NOTÍCIA. Madri, Espanha, edição de 19 de junho de 2005.

BATISTA, A. C.; SOARES R. V. Manual de prevenção e combate a incêndios florestais. Curitiba: Fundação de Pesquisas Florestais do Paraná, 2003. 52 p. 
BOTELHO, H. S. Efeitos do fogo controlado em árvores de povoamento jovens de Pinus pinaster. Vila Real, Portugal: UTAD, 1996.

FONSECA, E. M. B.; RIBEIRO, G. A. Manual de prevenção e controle de incêndios florestais. Belo Horizonte, CEMIG, 2003.

FUNDAÇÃO DO MEIO AMBIENTE DO ESTADO DE SANTA CATARINA (FATMA). Atlas da cobertura vegetal de Santa Catarina. Florianópolis, 2003.

FREY, W. Reflorestar é a solução. Curitiba: Sépia. 2003.

HEIKKILA, T. V.; GRONQVIST, R.; JUERVELIUS, M. Handobook on Forest fire control: a guide for trainers. Helsinki: [S.N.], 1993. 239 p. (Forestry Training Program, n. 21).

JESUS, D. E. Direito Penal. São Paulo: Saraiva. 1985.

LACOWICZ, A. Bombeiro Comunitário a Parceria que deu certo. Chapecó: Imprimax, 2002.

MAUS, A. Proteção Contra Incêndio: atividades técnicas no Corpo de Bombeiros - teoria geral. Florianópolis: Editograf, 1999.

SANTA CATARINA. Decreto $\mathbf{n}^{0} 4909$ de 09 de outubro de 1994. Estabelece as normas de segurança contra incêndios do Estado de Santa Catarina.

SANTOS, J. F. Estatísticas de incêndios florestais em áreas protegidas no período de 1998 a 2002.76 f. Dissertação (Mestrado em Engenharia Florestal) - Setor de Ciências Agrárias, Universidade Federal do Paraná, Curitiba, 2004.

SOARES, R. V. Determinação de um índice de perigo de incêndio para a região centro-paranaense, Brasil. 72 f. Dissertação (Mestrado) - Instituto Interamericano de Ciências Agrícolas da OEA. Departamento de Ciências Florestais/Centro Tropical de Ensino e Investigação, Turrialba, 1972.

SOARES, R. V. Incêndios Florestais, controle e uso do fogo, Curitiba, Fundação de Pesquisas Florestais, 1985. $213 \mathrm{p}$.

SOARES, R. V.; BATISTA, A. C. Combustão da Biomassa e Propagação dos Incêndios. Brasília, ABEAS/UFPR, 2001. Curso de Especialização, Módulo II.

SOARES, R. V.; BATISTA, A. C. Prevenção dos Incêndios Florestais. Brasília, ABEAS/UFPR, 2001b. Curso de Especialização, Módulo II..

SOARES, R. V.; BATISTA, A. C. Combate aos Incêndios Florestais. Brasília: ABEAS/UFPR, 2001c. Curso de Especialização, Módulo II.

SOARES, R. V.; BATISTA, A. C. Incêndios Florestais: controle, efeitos e uso do fogo. Curitiba, 2007. 250 p.

SOARES, R. V.; SANTOS, J. F. Perfil dos incêndios florestais no Brasil, de 1994 a 1997. Floresta, Curitiba, v. 32, n. 2, p. 219-232, 2002.

SOARES, R. V.; BATISTA, A. C.; SANTOS, J. F. Evolução do perfil dos incêndios florestais em áreas protegidas no Brasil, de 1993 a 2002. In: SEMINÁRIO DE ATUALIDADES EM PROTEÇÃO FLORESTAL. 2., 2005 Blumenau. Anais do... Curitiba: FUPEF, 2005.

VÉLEZ, R. M. La defensa contra incendios forestales - fundamentos y experiencias. Madrid: McGraw-Hill, 2000. 